\title{
A PRIMER ON
}

\section{Translating veterans' training into civilian job skills}

During their military careers, veterans receive extensive, full-time training not only in technical specialties but in valuable nontechnical (or soft) skills, such as leadership, decisionmaking, persistence, and communication. These skills are vital to success in the civilian workforce, but translating military terminology into civilian workplace parlance can be challenging. Here are two examples of how training can translate.

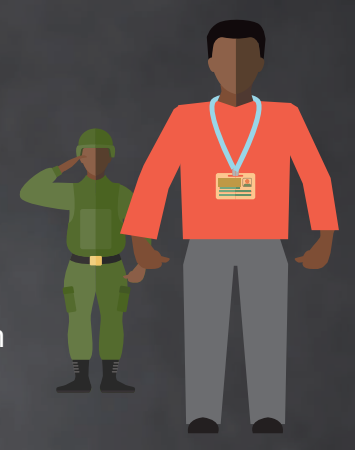

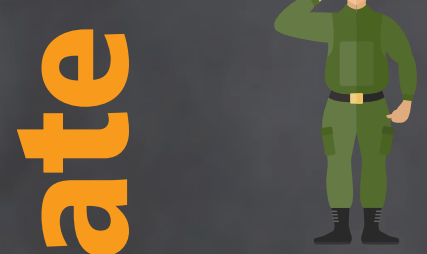

\section{MILITARY TRAMIING} RECEIVED

Army Basic Combat Training (10-week course)

- Participating in dangerous, demanding exercises

- Completing tasks quickly to support team success

- Mastering tasks that require extensive practice

- Following exacting standards with precision

- Working collaboratively with others around the clock

- Cooperating with peers from diverse cultural backgrounds

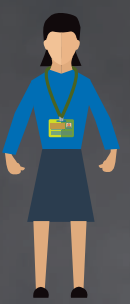

\section{SKILLS EMPLOYERS}

WANT

Entry-level

civilian job skills

- Handling work stress

- Being dependable and reliable

- Persistence

- Conscientiousness and attention to detail

- Teamwork and team-building

- Interpersonal skills

\section{MILTARY TRAMUIN RECEIVED}

Marine Corps Sergeants Course

(7-week course)

- Giving extemporaneous speeches

- Developing a plan of action despite uncertainty

- Gaining buy-in from peers

- Debating, considering, and reconsidering positions

- Writing and revising analytical essays

- Learning how to create long-range, annual, and quarterly training plans

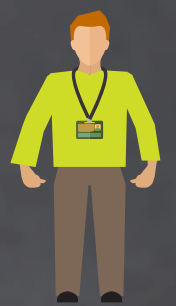

\section{SKILLS EMPLOYERS} WANT

Mid- to senior-level

civilian job skills

- Oral communication

- Decisionmaking/decisiveness

- Leading, motivating, and inspiring others

- Critical thinking

- Written communication

- Training others

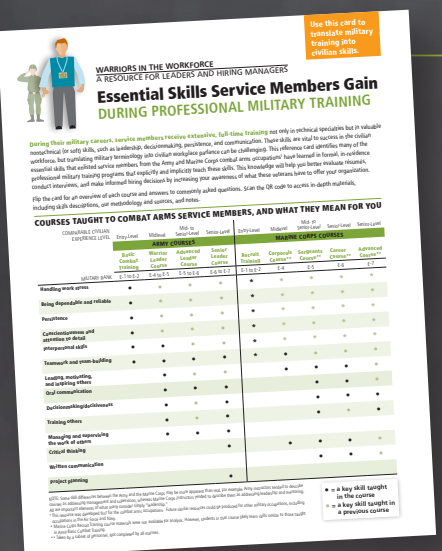

Excerpted from Essential Skills Service Members Gain During Professional Military Training: A Resource for Leaders and Hiring Managers, by Chaitra Hardison et al., RAND Corporation, TL-160/2-OSD, 2015

www.rand.org/t/TL160z2

The RAND Corporation is a research organization that develops solutions to public policy challenges to help make communities throughout the world safer and more secure, healthier and more prosperous. RAND is nonprofit, nonpartisan, and committed to the public interest. 


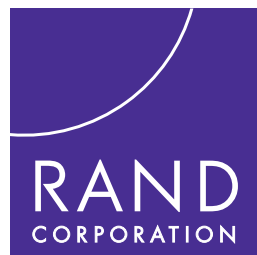

CHILDREN AND FAMILIES

EDUCATION AND THE ARTS

ENERGY AND ENVIRONMENT

HEALTH AND HEALTH CARE

INFRASTRUCTURE AND

TRANSPORTATION

INTERNATIONAL AFFAIRS

LAW AND BUSINESS

NATIONAL SECURITY

POPULATION AND AGING

PUBLIC SAFETY

SCIENCE AND TECHNOLOGY

TERRORISM AND HOMELAND SECURITY
The RAND Corporation is a nonprofit institution that helps improve policy and decisionmaking through research and analysis.

This electronic document was made available from www.rand.org as a public service of the RAND Corporation.

\section{Support RAND}

Browse Reports \& Bookstore

Make a charitable contribution

\section{For More Information}

Visit RAND at www.rand.org

Explore the RAND Corporation

View document details

\section{Infographic}

RAND infographics are design-focused, visual representations of data and information based on a published, peer-reviewed product or a body of published work.

\section{Limited Electronic Distribution Rights}

This document and trademark $(s)$ contained herein are protected by law as indicated in a notice appearing later in this work. This electronic representation of RAND intellectual property is provided for noncommercial use only. Unauthorized posting of RAND electronic documents to a non-RAND website is prohibited. RAND electronic documents are protected under copyright law. Permission is required from RAND to reproduce, or reuse in another form, any of our research documents for commercial use. For information on reprint and linking permissions, please see RAND Permissions. 